\title{
Ex-post Evaluation and Sectoral Policy, with particular reference to Dairy Development in Nigeria
}

\section{Frank A. Wilson}

Increased interest recently in improving and refining development project planning and management practice has also stimulated greater interest in the methods and procedures of ex-post evaluation. The IBRD has, for example, recognised this not only in commissioning Uma Lele's valuable study of World Bank assisted projects (Lele 1975) but also by encouraging borrowing countries (and others) to incorporate evaluation units into project development and management teams (Willoughby 1977). The British Ministry of Overseas Development has also recognised the need for formalised evaluation studies and has embarked upon a programme of work utilising university staff. Some writers who have evaluated on-going schemes and projects have questioned the extent to which further refinements of appraisal methodology, and especially those concentrated on social cost-benefit analysis applications, are justified, and argue that scarce planning resources could be better employed in other areas (Carruthers and Clayton 1977; Desai 1977; Rondinelli 1976). Although the writer shares this view, it is increasingly necessary to look for constructive ways of suggesting how the emphasis should be shifted.

It is not difficult to find examples of projects where problems of 'implementation' are cited. Implementation is, however, a portmanteau word which can mean different things to different people - and is often required to do so. An implementation problem can be said to occur when some activity has not taken place as planned and/ or has not achieved the purpose for which it was carried out. Within this loose definition we can incorporate a whole range of performance indicators, from adverse technical input-output relationships to overspending of budgeted funds. Such is the complex and dynamic nature of development projects, however, that the real nature of the implementation problem may not be readily or easily apparent. To what extent is a lower than planned level of technical performance caused by ineffective day-to-day management or late delivery of inputs due to a cumbersome ordering and accounts system? To what extent are both causes secondary to faulty initial planning which based technical performance levels on over-optimistic assumptions? Different projects throw up different implementation problems, but attempts to solve them have a common operational significance. Principally this entails a distinction between improving in-built monitoring and control procedures as part of the overall project management function, and ex-post evaluation as an aid to sector policy formulation and a device for improving programme management (Turner 1976).

Although there may appear to be no clear demarcation line between monitoring and control and ex-post evaluation, it has to be remembered that a predominant feature of public sector project planning is the nature of the planning and implementation machinery within which projects fit. Whereas the private entrepreneur may identify, prepare and appraise his own projects and then proceed to manage and evaluate them himselfor through a management team-the public sector project may be identified and prepared by one department, appraised by another, managed by a newly created management agency, and evaluated by another department which may or may not have been involved in the initial planning of the scheme. Thus the separateness of those parts of the government machine responsible for these different planning and management activities is an integral part of public sector planning. There are ways in which systems could be rationalized to reduce the number of links and improve communication between those that remain, but a partial (at best) acceptance of the structure appears necessary. This understanding and acceptance requires an awareness of the limited amount of direct feedback from the on-going project to those who may be required to identify and appraise new ones in the same sectoral or subsectoral area.

For public sector projects, planned and recognised ex-post evaluation procedures would thus appear to be necessary. In the contrasting situation of the individual entrepreneur, ex-post evaluation is an automatic reassessment which may not even be committed to paper, and the feedback mechanism is a direct one, whereas in many public sectors, large and small, it is essentially indirect,

Recent advisory work to assist in carrying out expost evaluation studies of projects in the livestock sector of Nigeria gave the writer the opportunity 
to examine the role of such studies in the formulation of new project initiatives and in reviewing sectoral policy. The commissioned studies ${ }^{1}$ were also expected to include specific recommendations for the improvement of the projects concerned. The terms of reference were almost identical for the five projects examined: 2

to evaluate the technical and economic feasibility of the projects and make recommendations for future planning and the improvement of the existing schemes.

The technical evaluation, carried out in the main by Nigerian university staff, concentrated upon animal production, health, research (where appropriate), processing and technical management. The economic evaluation, carried out in the main by the writer, was concerned with assessing commercial and financial viablity, relating this to the broader objectives of the projects and sectoral policy and then assessing their impact as a guide to future planning.

\section{The Maiduguri dairy project}

Following in part the recommendations of $\mathrm{FAO}^{3}$, the Nigerian Government has in recent years placed some emphasis on increasing the share of marketed milk from local production as opposed to that (major) portion coming from imports of tinned milk, milk powder and dairy products. This was reflected in the projects and schemes included in the Federal and State 1975-80 Development Plans and has more recently been intensified under the 'Operation Feed the Nation' (OFN) campaign. The underlying philosophy of OFN is an increased degree of self-reliance in food production, although the major initiatives so far have come in crop rather than livestock areas. The Maiduguri Dairy study provides a good example of the problems for the analyst inherent in this type of project. At the same time it demonstrates in a direct way the extent to which the planning and execution of such projects is handicapped by the lack of any consistent policy framework.

Maiduguri is situated in the North-East of Nigeria and is the capital of what is now Borno State.

1 Federal Livestock Department, Dairy, Beef and Vaccine Project Expost Evaluation Report, Government Printer, Kaduna March 1976.

2 Maiduguri Dairy, Maiduguri, Borno State;

Vom Dairy Farm. Federal Department of Veterinary Research, Vom, Plateau State:

Obudu Cattle Ranch Development Corporation, Cross River State; Agege Dairy, Agege, Lagos State;

Aaccine Production Scheme, Federal Department of Veterinary Research, Vom, Plateau State.

3 FAO International Scheme for Co-ordination of Dairy DevelopmentNigeria Report, Rome, September 1975.
The milk receiving and pasteurisation plant was commissioned in 1973 after a long period of assessment and re-assessment first begun in 1963 by the then Northern Regional Government. No recognisable project document was produced, but the declared objectives of the scheme were that it should function as a processing and marketing intermediary for local producers and as a source of hygenic milk and milk products for the people of Maiduguri.

There were therefore three sets of objectives:

Local Welfare-improved consumption through clean milk and hygienic milk products;

Production-increased local supplies;

Development-establishing regular markets for local cattle keepers.

Before assessing how the project as evaluated satisfied these objectives it is helpful to consider the governmental framowork within which the scheme operated. It should be noted that there was no declared policy on the extent to which the project should be profitable or operate on a breakeven basis, or whether a continuing financial deficit was acceptable. One special feature of commercially based projects of this kind, operated from within the public sector, is that they become absorbed into the ongoing structure of departmental government administration. This has the effect of masking financial performance by means of adherence to established accounting procedures and encourages officials to beg the question as to whether viability-or some recognised limit on financial subsidy-should be sought after. At the time of the evaluation in January and February, 1976, the project was operated by the State Ministry of Agriculture and Natural Resources. Management was under the direct control of a Senior Livestock Officer and financial provision was through a departmental recurrent vote item. All revenue was paid into the Government Treasury and was not used by the project to meet direct expenses. All staff other than occasional casual workers were on the permanent establishment of the Agricultural Department. All vehicles were Departmental 'pool' vehicles and their specific allocation to the project was limited.

The welfare objective was achieved only to a very limited degree. Some value could be attached to the provision of hygienic uncontaminated milk rather than the untreated and of ten unclean product sold locally. The share of the total market taken by the dairy was, however, relatively small. It was also apparent that those purchasing 
pasteurised milk and nono (yoghurt) were predominantly from middle and higher income groups who substituted the 'improved' local products for imported tinned liquid and powdered milk. The consumer welfare objective could not be looked at only in public health terms, and, as will be shown below, the plant was not able effectively to enter the lower income urban market due mainly to a grossly inadequate supply pattern. Nutritionally the need ${ }^{4}$ was for a higher per capita consumption and improved distribution of total animal protein. In terms of filling a nutritional gap it mattered little whether this was met from locally produced liquid milk, imported dried milk, or a combination of the two. If nutritional targets were to be reached, the only way that this could be achieved in the short and medium term was through a large increase year by year in the importation of milk and milk products.

The extent of the achievement of the self-reliance or production objective could not, then, be considered.in isolation from the welfare objective. In the case of the Maiduguri Dairy Project it was difficult to ascertain the level of incremental production as a result of the scheme. The raw milk collection service had undoubtedly provided a more organised marketing system than that which was, and is, operated by many local milk and nono traders. The dairy plant paid marginally better prices and provided a direct cash payment. It appeared likely that, from the producers' point of view, these advantages more than compensated for the more stringent quality standards required, and that in consequence there was a considerable diversion of supply from traditional trading channels, and only a small increment in supply due to the project itself.

It has already been noted that one purpose of the evaluation was to enable relevant recommendations to be made about dairy development policy during the Third Plan period. The (then) NorthEastern State Government had allocated 19 per cent of total livestock projects, capital expenditure to dairy schemes, including the establishment of 14 units modelled on the Maiduguri plant ${ }^{5}$. The objective behind locating the units in different parts of the State appeared predominantly production oriented, particularly as provision had been made for each pasteurisation unit to be

\footnotetext{
4 FAO estimated that in 1972 the total consumption of cows' milk and milk products was equivalent to $11 \cdot 0 \mathrm{~kg}$. per caput as against a nutritionally desirable level of $22 \cdot 0 \mathrm{~kg}$. per caput.

5 North-Eastern State Third National Development Plan 1975-80 Public Sector Programmes, Military Governor's Office, Maiduguri, 1975.
}

complemented by the establishment of a government-run dairy farm. This was a clear recognition that, as the financial analysis of the Maiduguri plant demonstrated, local supply from individual cattle keepers was insufficient to maintain a commercially viable level of throughput with the technology adopted. But the technical constraints on large-scale commercial dairying in Nigeria are such that milk production units of the type planned are unlikely to be commercially viable. Production on this scale would, therefore, have to be underwritten by the State or Federal Government over a considerable number of years, and possibly indefinitely. A very high premium would have to put on net foreign exchange savings and the small amount of employment created in order to justify such initiatives in social cost-benefit terms.

On the other hand the Maiduguri project had clearly gone some way towards meeting recognisable developmental objectives at the level of the individual citizen. Over the life-time of the project, in excess of 65 per cent (on average) of milk supplied had come from small settled and semisettled cattle keepers for whom the establishment of a regular market outlet was likely to be of considerable significance. Of equal importance was the opportunity which regular contact with producers gave for the provision of technical advice, supplementary feeds, improved bulls, milk quality improvement, and animal health checks. In the nomenclature of project appraisal these benefits may be categorised as externalities, particularly as they were not recognised at the planning stage and have received little recognition since the project began. They help to highlight the distinction between 'production' and 'development' and demonstrate that one does not necessarily follow from the other. In this case, as indicated above, the direct production orientation of planners was unlikely to bring with it the low-level small-scale development which deprived rural areas so desperately need.

The Maiduguri project evaluation, described here briefly and selectively, appears to demonstrate the way in which those responsible for ex-post studies can not only seek to improve existing projects and advise specifically on the planning of new ventures but also throw valuable light on the underlying policy issues. The methodology of such studies is relatively unsophisticated and the work involved is often tedious and unattractive. However, if we are to learn more about the real reasons for the success or failure of our planning efforts, this kind of work, consistently applied, must increasingly be carried out. 